\title{
The effect of generalized and specific expectancies upon eyelid conditioning
}

DOLORES GOLD

UNIVERSITY OF SASKATCHEWAN

Four groups of $S s$ differing with respect to $I-E$ scores (generalized expectancies) and set (specific expectancies) were run 70 trials in an eyelid conditioning experiment. It was predicted that the interaction between sets and I-E scores would determine conditioning level with Ss in conditions of matching generalized and specific expectancies conditioning at a high level than Ss in conditions of conflict between generalized and specific expectancies. The hypothesis received some support (probability at the .10 level), with differences among groups being in the predicted direction.

A social learning theory (Rotter, 1954; Rotter, Seeman, \& Liverant, 1962) has produced a basic concept that should be relevant to most learning and work situations. This concept has to do with generalized expectancies for internal as opposed to external control of reinforcement. The degree to which an individual perceives the reinforcement as contingent upon his own behavior as opposed to the degree to which he perceives reinforcement as controlled by forces external to him, and consequently able to occur independently of his actions, partly determines the effect of the reinforcement and the behavior of the individual in the situation.

The Internal-External Scale (I-E Scale) has been developed to measure this tendency to attribute reinforcement to one's own actions or to luck, chance, and other such external forces. Rotter (1966) has summarized the reliabllity and validity data for the scale as well as available research results. He concluded that there is evidence that internal scoring Ss are more alert to possibilities of and more active in improving their environmental conditions than external scoring Ss.

However, generalized expectancies function within stimuli situations and the particular expectancies evoked by these situations, which may or may not conflict with generalized tendencies. Based upon Rotter's social learning theory (1954), it is postulated that the individual's generalized expectancies for control would interact with specific expectanies evoked by particular situations to determine behavior within that situation. The basic hypothesis of this study is that when internal scoring Ss (internals) or external scoring Ss (externals) are given specific internal or extermal sets in the instructions on a conditioning task, Ss in those conditions where set and I-E tendency match will condition most effectively. That is, differences among groups should be due to the interaction effects between generalized and specific expectancies.

\section{Method}

Subjects and design. Students in introductory psychology courses were given the I-E Scale and students scoring in the upper and lower $10 \%$ range of scores were randomly assigned to groups and used as Ss. If a $\mathrm{S}$ was lost during the conditioning procedure, he or she was replaced by another $S$ who had also scored in the appropriate $10 \%$ range of scores. Three Ss were discarded due to apparatus difficulty during their conditioning trials, and one additional $S$ was discarded due to a very high base rate of spontaneous blinking. Using a temporal criterion (Spence \& Ross, 1959), two other Ss were classed as voluntary responders and discarded. Sixty-four Ss, 32 intermals and 32 externals, composed of equal numbers of males and females, provided the data for analysis.

The experimental design was a 2 by 2 factorial with half the internals and half the externals receiving internal set directions, and the other halves receiving external set directions. Male and female Ss were also equally represented in the conditions. Thus, there were four groups: internals under internal set; externals under external set; internals under external set; and externals under internal set.

Conditioning Procedure. Each $\mathrm{S}$ was individually tested in a sound treated, dimly illuminated (2.5 ft-c) testing booth. The $S$ sat at a table in a specially designed chair with an adjustable head holder. The E administered the conditioning trials from an adjacent room.

The CS was an increase in brightness of a diffused red disc $15 \mathrm{~mm}$ in diameter lasting $500 \mathrm{msec}$. The UCS was a puff of air of 2.0 psi produced by a system consisting of a compressed air cylinder, an air regulator, and a solenoid operated air valve. The puff was delivered to the cornea of the S's left eye by a $2 \mathrm{~mm}$ plastic tube. The UCS overlapped with the CS and lasted for $60 \mathrm{msec}$. The CS-UCS interval, therefore, was $440 \mathrm{msec}$. The onset and durations of the CS and UCS were controlled by Hunter interval timers.

Eyeblinks were recorded by a pair of silver disc electrodes attached above and below the left eye. The potential change in lid movement was amplified and recorded by a Grass $5 D$ polygraph.

After the equipment was adjusted and the instructions read to the $S$, each $S$ received three presentations of the CS alone, followed by a single presentation of the UCS. The conditioning trials began about 1 min later.

At random intervals of 2, 3, or $4 \mathrm{sec}$ before the CS was presented, the word "ready" was spoken. At this 


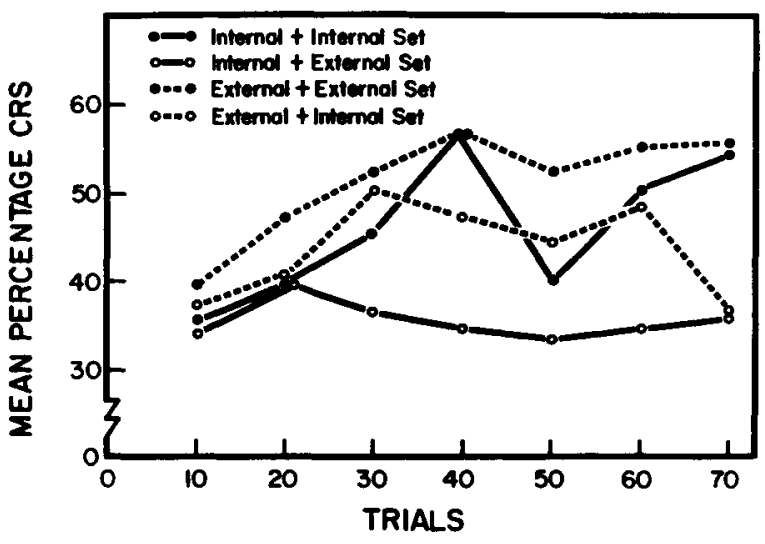

Fig. 1. Mean percentage crs as a function of number of trials.

signal the $S$ was instructed to blink once and to fixate the disc. A total of 70 conditioning trials were then given, with the intertrial interval averaging $20 \mathrm{sec}$. All eyelid closures occurring between 300 and 500 msec were considered CRs.

Instructions. Immediately after being seated and having the equipment adjusted, the instructions were read to the $S$. The first part of the instructions, in which all Ss were given a brief description of conditioning, were based on those of McAllister \& McAllister (1958). It is probable that some of the Ss had knowledge of conditioning and therefore it was desirable that an attempt be made to standardize Ss' knowledge of conditioning. In addition, it was considered that subject knowledge of conditioning would maximize the effects of expectancies.

The directions for internally controlled set were as follows: "We want your natural untrained reactions. Some people condition much better than others and how well people do in this experiment seems to be a func-

Table 1.

Analysis of Variance of Percentages of CRs in Last 20 trials

\begin{tabular}{lrrr} 
Source & df & \multicolumn{1}{c}{ MS } & $F$ \\
\hline Set & 1 & .39 & $<1$ \\
I-E Scores & 1 & 172.26 & $<1$ \\
Set X I-E Scores & 1 & $4,472.27$ & 2.92 \\
Error & 60 & $1,535.49$ & \\
\hline
\end{tabular}

tion of their general ability. That is, how well you do depends entirely upon your own ability. Sit quietly throughout the experiment and don't move."'

The directions for externally controlled set were as follows: "Some people condition better than others, but we can't relate this to any characteristics of these people. To a very large extent it seems that conditioning is not within the control of the subject -it either happens or it doesn't. So just sit quietly and make yourself as comfortable as you can, but don't move throughout the experiment."

\section{Resulis and Discussion}

Figure 1 presents the conditioning performance of the four groups plotted as a function of blocks of 10 trials. Table 1 presents a factorial analysis of variance for the mean percentage of CRs during the last 20 trials. As predicted, there were no significant main effects. Interaction between set and I-E scores shows a tendency towards significance, with probability at the .10 level. Figure 1 indicates that differences among groups tend to be in the predicted direction, with externals under external set and internals under internal set tending to condition at higher levels.

There is, therefore, some support for the hypothesis that Ss will condition at higher levels in conditions where their generalized expectancies match the speciflc expectancies evoked by the situation than in conditions of conflict between generalized and situational expectancies. Since generalized expectancy is a fundamental personality variable, it may have an effect in all learning situations, and its influence should be further examined.

\section{References}

Mc.Allister, W. R., \& McAllister, D. E. Effect of knowledge of conditioning upon eyelid conditioning. J. exp. Psychol., 1958, 55, 579-583.

Rotter, J. B. Social learning and clinical psychology. Englewood Cliffs: Prentice-Hall, 1954.

Rotter, J. B. Generalized expectancies for internal versus external control of reinforcement. Psychol. Monogr., 1966, 80, No. 1.

Rotter, J. B., Seeman, M., \& Liverant, S. Internal versus external control of reinforcement: A major variable in behaviour theory. In N. H. Washburne (Ed.), Decisions, groups and values. New York: MacMillan Company, 1962. Pp. 473-517.

Spence, K. W., \& Ross, L. E. A methodological study of the form and latency of eyelid responses in conditioning. $J$. exp. Psychol., $1959,58,376-381$. 